\title{
Short communication: Evaluation of a sol-gel-based stainless steel surface modification to reduce fouling and biofilm formation during pasteurization of milk
}

\author{
Dylan Zhe Liu, ${ }^{*}$ Shivali Jindal, $†$ Jayendra Amamcharla, ${ }^{* 1}$ Sanjeev Anand, $\dagger$ and Lloyd Metzger† \\ *Department of Animal Sciences and Industry/Food Sciences Institute, Kansas State University, Manhattan 66506 \\ †Midwest Dairy Foods Research Center, Dairy and Food Science Department, South Dakota State University, Brookings 57007
}

\section{ABSTRACT}

Milk fouling and biofilms are common problems in the dairy industry across many types of processing equipment. One way to reduce milk fouling and biofilms is to modify the characteristics of milk contact surfaces. This study examines the viability of using Thermolon (Porcelain Industries Inc., Dickson, TN), a sol-gel-based surface modification of stainless steel, during thermal processing of milk. We used stainless steel 316L (control) and sol-gel-modified coupons in this study to evaluate fouling behavior and bacterial adhesion. The surface roughness as measured by an optical profiler indicated that the control coupons had a slightly smoother finish. Contact angle measurements showed that the modified surface led to a higher water contact angle, suggesting a more hydrophobic surface. The modified surface also had a lower surface energy $(32.4 \pm 1.4 \mathrm{mN} / \mathrm{m})$ than the control surface $(41.36 \pm 2.7 \mathrm{mN} / \mathrm{m})$. We evaluated the susceptibility of control and modified stainless steel coupons to fouling in a benchtop plate heat exchanger. We observed a significant reduction in the amount of fouled layer on modified surfaces. We found an average fouling weight of $19.21 \mathrm{mg} / \mathrm{cm}^{2}$ and $0.37 \mathrm{mg} / \mathrm{cm}^{2}$ on the control and modified stainless steel coupons, respectively. We also examined the adhesion of Bacillus and biofilm formation, and observed that the modified stainless steel surface offered greater resistance to biofilm formation. Overall, the Thermolon-modified surface showed potential in the thermal processing of milk, offering significantly lower fouling and bacterial attachment than the control surface.

Key words: milk deposit, bacterial attachment, thermal processing, surface treatment

Received October 11, 2016.

Accepted December 4, 2016.

${ }^{1}$ Corresponding author: Jayendra@ksu.edu

\section{Short Communication}

Milk fouling and biofilms are expensive and persistent problems for the dairy industry (Baier, 2006; Mérian and Goddard, 2012). Fouling of milk components is a common occurrence across many types of dairy processing equipment (e.g., plates, pipes, and flow channels; Sadeghinezhad et al., 2015). Previous studies have stated that the effect of fouling on the dairy industry accounts for up to $80 \%$ of total operating costs (Bansal and Chen, 2006). Fouling during pasteurization of milk on the stainless steel surfaces of plate heat exchangers can be classified as type A fouling, consisting of 50 to $60 \%$ proteins and 30 to $35 \%$ minerals. Fouling necessitates frequent clean-in-place, leading to increased down time and reduced production (de Jong, 1997).

The fouling layer on stainless steel surfaces accelerates the adhesion of bacteria and encourages the development of biofilms (Simões et al., 2010). The formation of biofilms during milk processing can lead to food spoilage and economic losses (Bremer et al., 2006). The major components of biofilms include bacteria and extracellular polymeric substances produced by bacteria (Flint et al., 1997; Mittelman, 1998). The fouled layer and extracellular polymeric substances guard the microorganisms and help them survive most of the cleaning protocols used in the dairy industry. Biofilms formed by Bacillus spp. are resistant to high stress, are very hydrophobic, and can easily attach to processing equipment (Faille et al., 2002; Simões et al., 2010).

One way to control undesirable fouling and biofilms is to modify the surface properties of the processing equipment. Sol-gel surface modification converts inorganic liquid substances into a gel that can be applied on metal surfaces to improve the surface properties. Thermolon is a sol-gel-based surface modification developed from an inorganic ceramic polymer. According to its manufacturer (Porcelain Industries Inc., Dickson, $\mathrm{TN}$ ), "It is environmentally friendly, durable, and most importantly, it has been approved by the FDA as a food contact surface (FDA 21CFR 175.300)." The objective 
of the present study was to evaluate the effectiveness of Thermolon surface modification on mitigating fouling and adhesion of microorganisms during the thermal processing of milk.

Stainless steel $316 \mathrm{~L}$ coupons $(25.4 \mathrm{~mm} \times 25.4 \mathrm{~mm} \times$ $0.5 \mathrm{~mm}$ ) with a 2B finished surface were provided by Stainless Supply (Monroe, NC) and used to mimic the surface of a typical plate heat exchanger. Thermolon surface modification was done by Porcelain Industries (Dickson, TN).

We measured the contact angles of 3 liquids with known surface tension (Costanzo et al., 1990): water $(72.8 \mathrm{mN} / \mathrm{m})$, 1-bromonaphthalene $(44.4 \mathrm{mN} / \mathrm{m})$, and ethylene glycol $(48 \mathrm{mN} / \mathrm{m})$ on the stainless steel control and Thermolon-modified surfaces using a static method with a FTA 1000 B Drop Shape instrument (Portsmouth, VA) at room temperature.

Because $\gamma_{s}^{T O T}=\gamma_{s}^{d}+\gamma_{s}^{p}$ (where $\gamma_{s}^{d}$ and $\gamma_{s}^{p}$ are the dispersive and polar components of the solid surface energy, respectively), solid surface energy can be determined by combining Young's equation (Equation [1]) and the Owens-Wendt approach (Equation [2]; Santos et al., 2004):

$$
\gamma_{s l}^{T O T}=\gamma_{s}^{T O T}-\gamma_{l}^{T O T} \cos \theta
$$

where $\gamma_{s l}^{T O T}$ is the total interfacial surface tension between solid and liquid, $\gamma_{s}^{T O T}$ and $\gamma_{l}^{T O T}$ are the surface tension of the solid and the liquid, respectively, and the contact angle $\theta$; and

$$
\gamma_{s l}^{T O T}=\gamma_{s}^{T O T}+\gamma_{l}^{T O T}-2\left(\gamma_{l}^{d} \gamma_{s}^{d}\right)^{\frac{1}{2}}-2\left(\gamma_{l}^{p} \gamma_{s}^{p}\right)^{\frac{1}{2}}
$$

where $\gamma_{l}^{d}$ and $\gamma_{l}^{p}$ are the dispersive and polar contributions of the liquid (Table 1).

We determined the surface roughness of different substrates using a Wyko NT1100 Optical Profiler (VEECO, Tucson, AZ). The field of view was $450 \times$ $592 \mu \mathrm{m}$, and the results were reported as an average of duplicate samples, with 5 scans of each sample.
We conducted fouling experiments in a laboratorydesigned benchtop plate heat exchanger as shown in Figure 1, fitted with control and modified coupons, respectively. Different batches of raw milk were collected from the dairy plant at Kansas State University and kept at $4^{\circ} \mathrm{C}$ before use. Each batch of milk was divided into 2 for tests using control and Thermolon-modified stainless steel coupons. The milk inlet temperature was set at $40^{\circ} \mathrm{C}$, and the hot water temperature in the second water bath was maintained at $88-90^{\circ} \mathrm{C}$ to maintain the milk outlet temperature at $\sim 85^{\circ} \mathrm{C}$. Raw milk was pumped through the benchtop plate heat exchanger for $7.5 \mathrm{~h}$, with a flow rate of $22 \mathrm{~mL} / \mathrm{min}$. After each test, the plate heat exchanger was dissembled, and the weight of the milk deposit on the coupons was measured after air drying for $15 \mathrm{~min}$ by recording the difference in weight of the clean plates versus the air-dried fouled substrates.

We carried out scanning electron microscope analysis using the Hitachi S-3500N (Tokyo, Japan). Clean stainless steel coupons (control and modified) were analyzed directly at an accelerating voltage of $20 \mathrm{kV}$. Milk fouling on the coupons was air-dried at room temperature and then coated with a $10-\mathrm{nm}$ layer of $99 \%$ gold. The fouling layer was then observed at an accelerating voltage of $10 \mathrm{kV}$.

We used aerobic spore-forming Bacillus licheniformis (ATCC 6643) to develop biofilms on control and modified stainless steel coupons at $50^{\circ} \mathrm{C}$ using the method described in our previous study (Jindal et al., 2016). The biofilm embedded cells in $72 \mathrm{~h}$, and matured biofilms formed on control and modified stainless steel coupons were enumerated by swabbing an area of 6.45 $\mathrm{cm}^{2}$ and plating on brain heart infusion (BHI) agar plates (Jindal et al., 2016).

Milk fouling and biofilm formation tests were conducted in triplicate. We calculated milk deposit weight and bacterial counts as mean values and standard deviations. We compared fouling, bacteria attachment, and surface property results using SAS software (version 9.4; SAS Institute Inc., Cary, NC) and set the least significance difference at $P<0.05$.

Table 1. Surface tension values (mN/m; Costanzo et al., 1990; Santos et al., 2004) and contact angle for the liquids used on control and modified coupons ${ }^{1}$

\begin{tabular}{llrrrr}
\hline & & & \multicolumn{2}{c}{ Contact angle $\left(^{\circ}\right)$} \\
\cline { 5 - 6 } Liquid & $\gamma_{l}^{\text {TOT }}$ & $\gamma_{l}^{d}$ & $\gamma_{l}^{p}$ & Stainless steel & Thermolon \\
\hline Water & 72.8 & 21.8 & 51 & $82.9 \pm 1.2$ & $105.5 \pm 0.9$ \\
1-Bromonaphthalene & 44.4 & 44.4 & 0 & $21.7 \pm 1.0$ & $44.9 \pm 1.5$ \\
Ethylene glycol & 48 & 29 & 19 & $65.9 \pm 1.4$ & $72.4 \pm 0.8$ \\
\hline
\end{tabular}

${ }^{1}$ Values are an average of 9 measurements (3 distinct regions on 3 independent samples) \pm SE. $\gamma_{l}^{T O T}$ is the surface tension of the liquid; $\gamma_{l}^{d}$ and $\gamma_{l}^{p}$ are the dispersive and polar contributions of the liquid, respectively. 


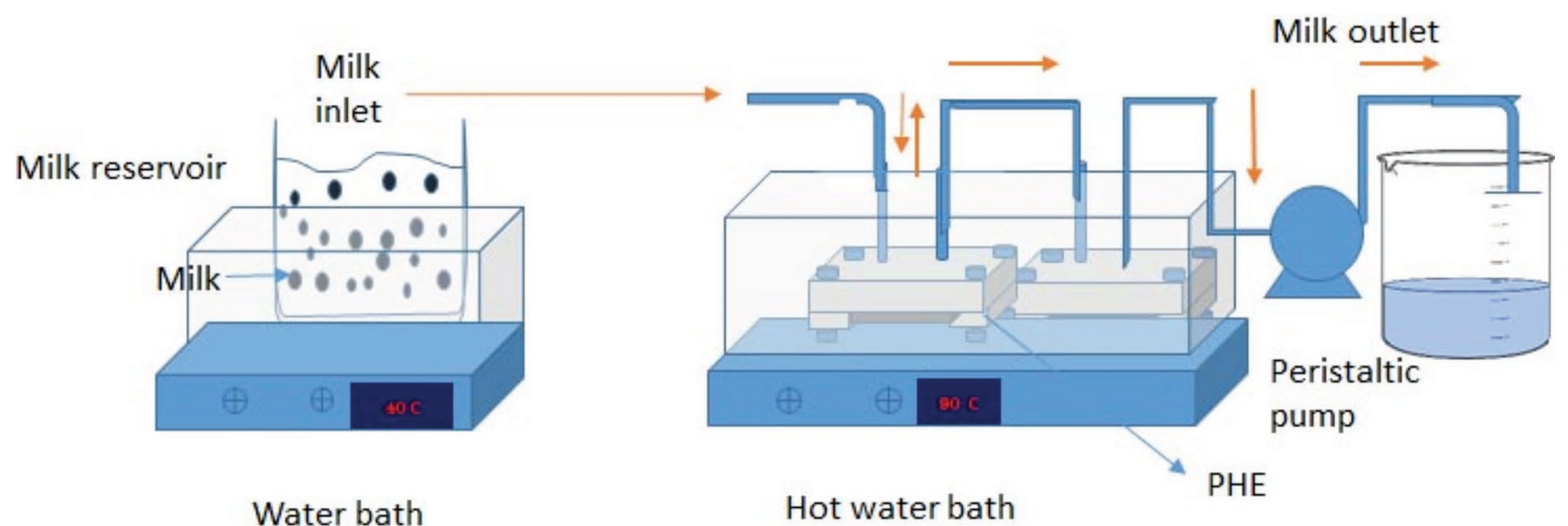

Figure 1. Schematic of the benchtop plate heat exchanger (PHE) setup to simulate milk pasteurization and generate milk fouling. Color version available online.

The properties of the milk contact surface play an important role in fouling and biofilm formation during dairy processing. We observed white, spongy-like deposit on control surfaces and less fouling on modified surfaces (Figure 2). The mean fouling weight on the control surfaces was $19.21 \pm 2.25 \mathrm{mg} / \mathrm{cm}^{2}$, and on the modified surfaces, it was $0.37 \pm 0.28 \mathrm{mg} / \mathrm{cm}^{2}$ (Table 2). Fouling weight was decreased up to $98 \%$ after sol-gel modification. We found more bacteria on control surfaces, at $\log 4.35 \mathrm{cfu} / \mathrm{cm}^{2}$; the modified surface showed a reduction to $\log 3.38 \mathrm{cfu} / \mathrm{cm}^{2}$ (Table 2).

When the water contact angle is over $90^{\circ}$, the surface is considered to be hydrophobic (Bhushan and Chae Jung, 2007). The water contact angle of control surfac- es was slightly below $90^{\circ}$, and the modified surface was more hydrophobic, with a contact angle of $105^{\circ}$ (Table $1)$. Early studies reported that less fouling and bacterial attachment were observed on hydrophobic surfaces (Fletcher and Loeb, 1979; Pringle and Fletcher, 1983; Jindal et al., 2016).

The surface energy of the contact surface also affects the fouling process (Sadeghinezhad et al., 2015). The relationship between fouling adhesion and material surface energy has been described by the Baier curve; substrates with surface energy $20-30 \mathrm{mN} / \mathrm{m}$ show the least atomic features of retention to protein deposition and bioadhesion (Baier, 2006). In the present study, the control surface had a surface energy of $41.36 \pm 2.7$
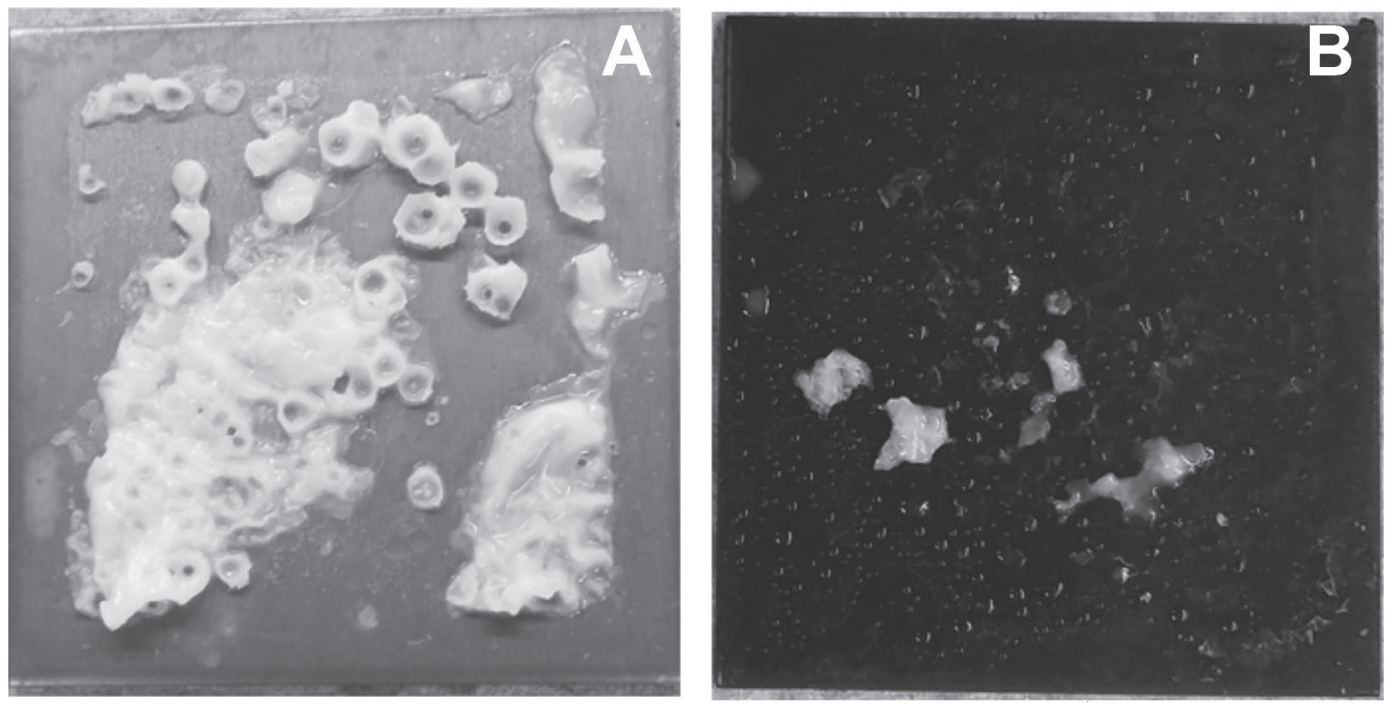

Figure 2. Representative images of fouling on (A) control and (B) Thermolon-modified stainless steel coupons after running raw milk for 7.5 $\mathrm{h}$ at $85^{\circ} \mathrm{C}$ in the benchtop plate heat exchanger. 
Table 2. Surface energy, surface roughness, average weight of milk deposit, and viable counts in biofilms on control and modified coupons

\begin{tabular}{lcccc}
\hline Sample & $\begin{array}{c}\text { Surface energy } \\
(\mathrm{mN} / \mathrm{m})\end{array}$ & $\begin{array}{c}\text { Surface roughness } \\
(\mathrm{nm})\end{array}$ & $\begin{array}{c}\text { Average weight of } \\
\text { milk fouling }^{3}\left(\mathrm{mg} / \mathrm{cm}^{2}\right)\end{array}$ & $\begin{array}{c}\text { Average counts in biofilms } \\
\left(\log _{10} \mathrm{cfu}^{3} / \mathrm{cm}^{2}\right)\end{array}$ \\
\hline Stainless steel & $41.36 \pm 2.70^{\mathrm{a}}$ & $148.6 \pm 15.0^{\mathrm{b}}$ & $19.21 \pm 2.25^{\mathrm{a}}$ & $4.35 \pm 0.07^{\mathrm{a}}$ \\
Thermolon & $32.40 \pm 1.40^{\mathrm{b}}$ & $199.0 \pm 10.6^{\mathrm{a}}$ & $0.37 \pm 0.28^{\mathrm{b}}$ & $3.38 \pm 0.10^{\mathrm{b}}$ \\
\hline
\end{tabular}

a,b Mean values within a column with different superscripts differ $(P<0.05)$.

${ }^{1}$ Surface energy values are the average of 3 independent samples \pm SE.

${ }^{2}$ Surface roughness values are the average of duplicate samples with 5 scans of each sample \pm SE.

${ }^{3}$ The values of milk fouling weight and bacterial counts in the biofilms were an average of 3 independent tests \pm SE.

$\mathrm{mN} / \mathrm{m}$, and that of the modified surface was lower, with a value of $32.40 \pm 1.4 \mathrm{mN} / \mathrm{m}$ (Table 2). This finding explains the easy-release property of the Thermolonmodified surface: it has a lower surface energy, close to the bio-fouling release zone (Baier, 2006).
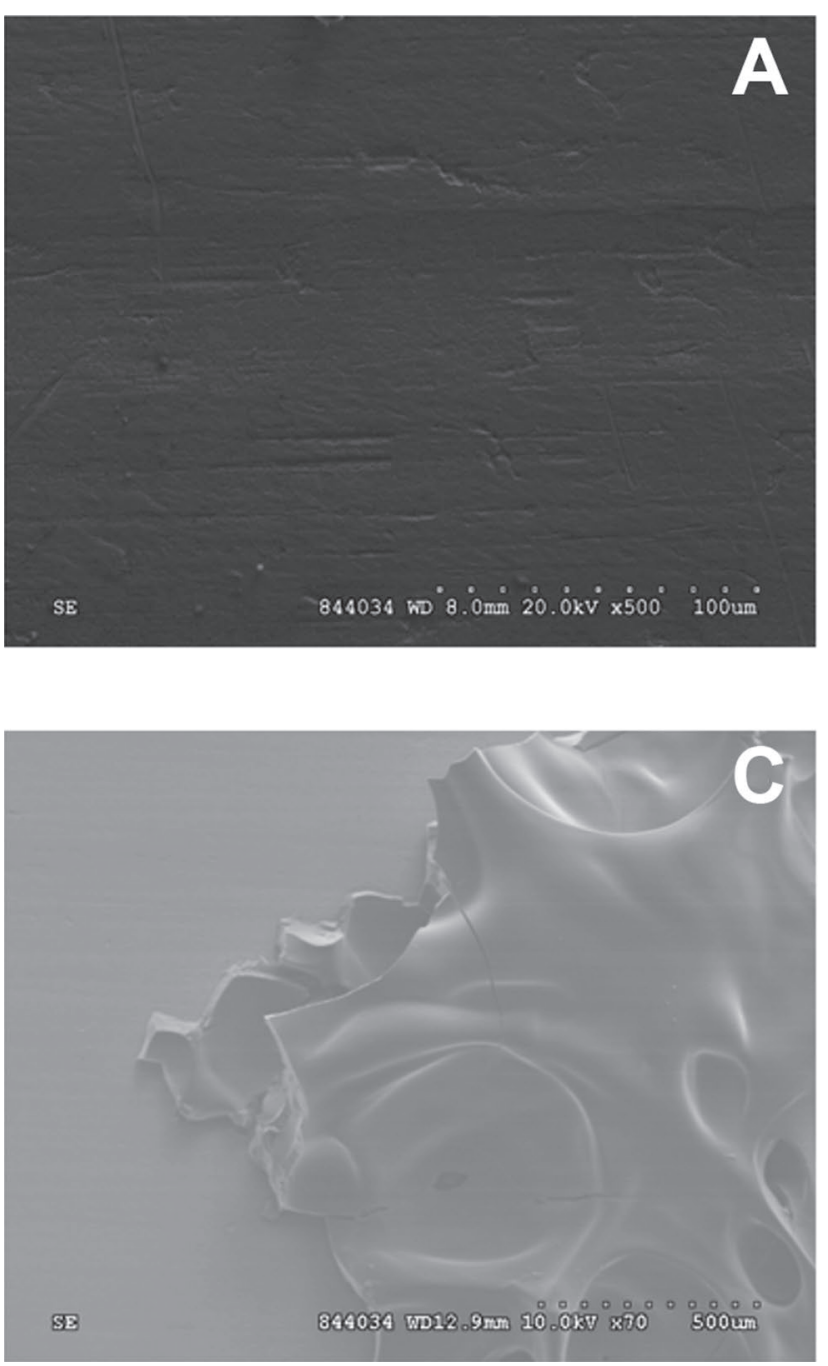

Scanning electron microscopy images were acquired to investigate surface morphology. As shown in Figure $3 \mathrm{~A}$, images of the $2 \mathrm{~B}$ finished stainless steel surfaces revealed cracks. This might have been due to the steps involved in producing the 2B surface: an annealing
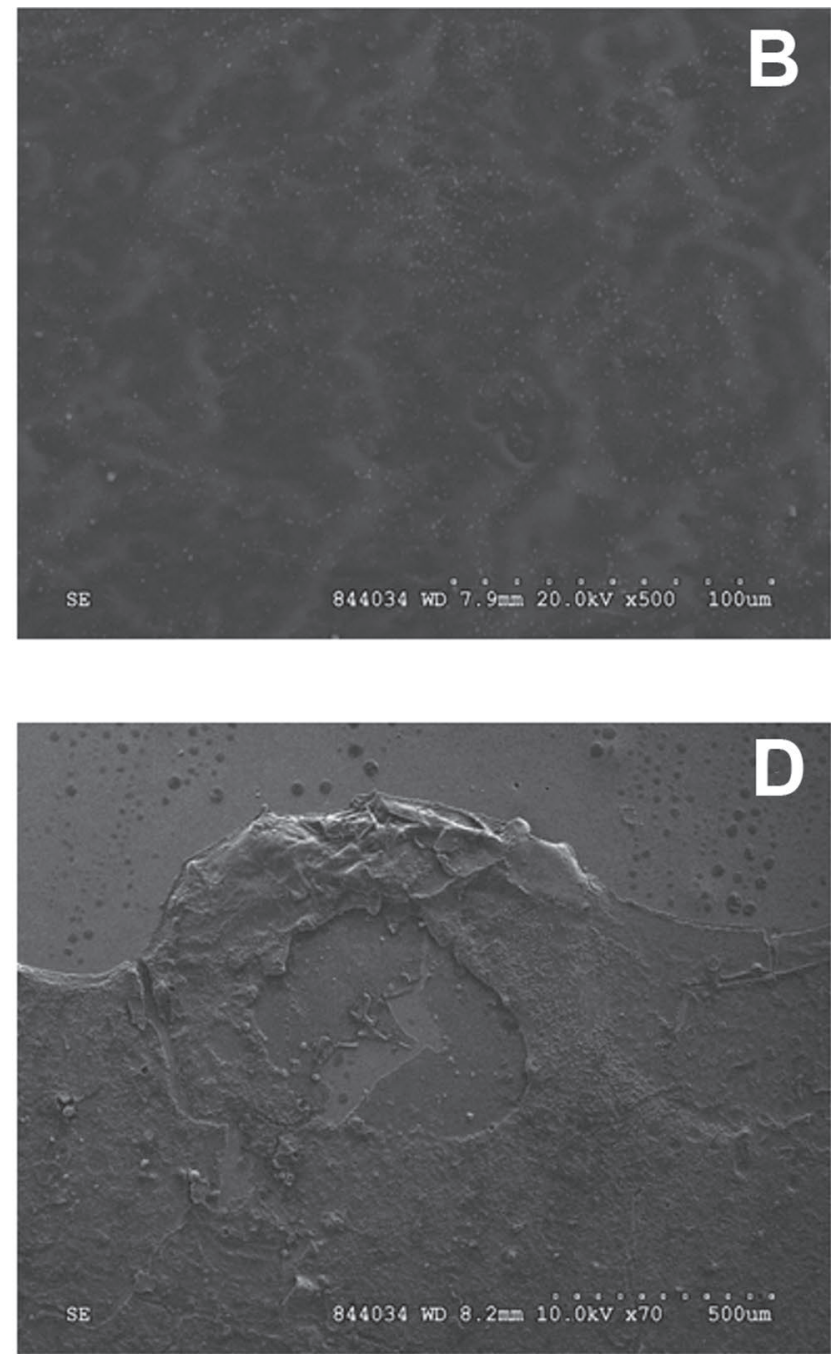

Figure 3. Scanning electron microscope images of clean and used coupons. (A) Clean control coupon; (B) clean Thermolon-modified coupon; (C) milk fouling on control coupon; (D) milk fouling on Thermolon-modified coupon. 
oxidizing atmosphere followed by picking to remove the oxide layer formed in the previous step (Frank and Chmielewski, 2001; Jullien et al., 2003). The sol-gel surface modification (Figure 3B) masked all surface characteristics of the stainless steel substrate, and the scanning electron microscope image showed a more heterogeneous topography, with no cracks on the top, leading to a more uniform surface. These surface differences could have led to the differences in the fouled microstructure. On the control surfaces, we observed thick and rugged milk deposits with sublayers and porous structures (Figure 3C), which might have been due to the fouling-induced heat transfer difference across the heat exchanger surface. On Thermolon-modified surfaces, the fouling layer was thinner and smooth, with small granules (Figure 3D).

Finally, the roughness of the modified surface was slightly higher (surface roughness $=199 \pm 10.6 \mathrm{~nm}$ ) than that of the control surface (surface roughness = $148.6 \pm 15.0 \mathrm{~nm}$; Table 2). There appears to be no direct correlation between surface roughness and biofouling formations (Tide et al., 1999).

Overall, the properties of the milk contact surface influenced the formation of milk deposit and biofilms. After Thermolon modification, the surface became more uniform and hydrophobic, with lower surface energy. Compared with the modified surface, we observed more milk fouling and bacterial attachment on the less hydrophobic control surfaces under the same conditions. These results provided evidence for the potential of using Thermolon-modified heat exchangers in dairy thermal processing to reduce milk fouling and biofilm formation, increasing process efficiency and enhancing the microbial quality of the final product.

The durability of surface modification is an important parameter for use in food-processing applications. In future studies, we will investigate the reusability of the Thermolon surface modification.

\section{ACKNOWLEDGMENTS}

This work was financially supported by the National Dairy Council. The authors also acknowledge Ravindra Thakkar from Kansas State University for scanning electron microscope analysis and Qiang Ye from Kansas University for surface roughness analysis. Contribution no. 17-113-J from the Kansas Agricultural Experiment Station.

\section{REFERENCES}

Baier, R. E. 2006. Surface behaviour of biomaterials: The theta surface for biocompatibility. J. Mater. Sci. Mater. Med. 17:1057-1062.

Bansal, B., and X. D. Chen. 2006. A critical review of milk fouling in heat exchangers. Compr. Rev. Food Sci. Food Saf. 5:27-33.

Bhushan, B., and Y. Chae Jung. 2007. Wetting study of patterned surfaces for superhydrophobicity. Ultramicroscopy 107:1033-1041.

Bremer, P. J., S. Fillery, and A. J. McQuillan. 2006. Laboratory scale Clean-In-Place (CIP) studies on the effectiveness of different caustic and acid wash steps on the removal of dairy biofilms. Int. J. Food Microbiol. 106:254-262.

Costanzo, P., R. Giese, and C. Van Oss. 1990. Determination of the acid-base characteristics of clay mineral surfaces by contact angle measurements - implications for the adsorption of organic solutes from aqueous media. J. Adhes. Sci. Technol. 4:267-275.

de Jong, P. 1997. Impact and control of fouling in milk processing. Trends Food Sci. Technol. 8:401-405.

Faille, C., C. Jullien, F. Fontaine, M.-N. Bellon-Fontaine, C. Slomianny, and T. Benezech. 2002. Adhesion of Bacillus spores and Escherichia coli cells to inert surfaces: Role of surface hydrophobicity. Can. J. Microbiol. 48:728-738.

Fletcher, M., and G. Loeb. 1979. Influence of substratum characteristics on the attachment of a marine pseudomonad to solid surfaces. Appl. Environ. Microbiol. 37:67-72.

Flint, S. H., P. J. Bremer, and J. D. Brooks. 1997. Biofilms in dairy manufacturing plant-description, current concerns and methods of control. Biofouling 11:81-97.

Frank, J. F., and R. Chmielewski. 2001. Influence of surface finish on the cleanability of stainless steel. J. Food Prot. 64:1178-1182.

Jindal, S., S. Anand, K. Huang, J. Goddard, L. Metzger, and J. Amamcharla. 2016. Evaluation of modified stainless steel surfaces targeted to reduce biofilm formation by common milk sporeformers. J. Dairy Sci. 99:9502-9513.

Jullien, C., T. Bénézech, B. Carpentier, V. Lebret, and C. Faille. 2003. Identification of surface characteristics relevant to the hygienic status of stainless steel for the food industry. J. Food Eng. 56:77-87.

Mérian, T., and J. M. Goddard. 2012. Advances in nonfouling materials: Perspectives for the food industry. J. Agric. Food Chem. 60:2943-2957.

Mittelman, M. W. 1998. Structure and functional characteristics of bacterial biofilms in fluid processing operations. J. Dairy Sci. 81:2760-2764.

Pringle, J. H., and M. Fletcher. 1983. Influence of substratum wettability on attachment of freshwater bacteria to solid surfaces. Appl. Environ. Microbiol. 45:811-817.

Sadeghinezhad, E., S. N. Kazi, M. Dahari, M. R. Safaei, R. Sadri, and A. Badarudin. 2015. A comprehensive review of milk fouling on heated surfaces. Crit. Rev. Food Sci. Nutr. 55:1724-1743.

Santos, O., T. Nylander, R. Rosmaninho, G. Rizzo, S. Yiantsios, N. Andritsos, A. Karabelas, H. Müller-Steinhagen, L. Melo, L. Boulangé-Petermann, C. Gabet, A. Braem, C. Trägårdh, and M. Paulsson. 2004. Modified stainless steel surfaces targeted to reduce fouling - Surface characterization. J. Food Eng. 64:63-79.

Simões, M., L. C. Simões, and M. J. Vieira. 2010. A review of current and emergent biofilm control strategies. LWT Food Sci. Technol. (Campinas) 43:573-583.

Tide, C., S. R. Harkin, G. G. Geesey, P. J. Bremer, and W. Scholz. 1999. The influence of welding procedures on bacterial colonization of stainless steel weldments. J. Food Eng. 42:85-96. 